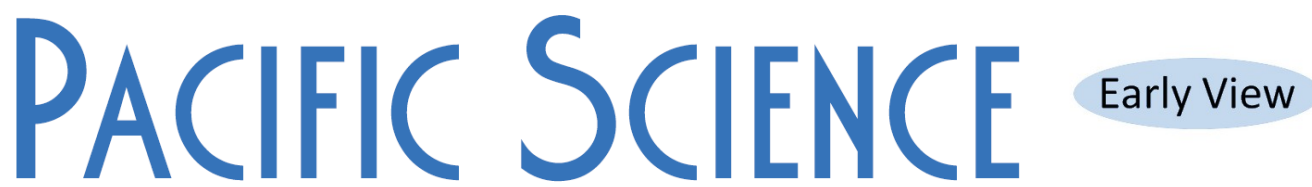

A Quarterly Devoted to the

Biological and Physical Sciences of the Pacific Region

\title{
The vulnerability of skinks to predation by introduced mongoose in the Fiji Islands
}

\author{
By Craig G. Morley and Linton Winder
}

\begin{abstract}
Skinks are successful colonisers and are commonly found throughout the Pacific islands, but, the presence of introduced predators such as mongoose are known to threaten their survival. The two most abundant skinks found within the Fiji Islands are Emoia cyanura and E. impar; the abundance of these species encountered during visual transect counts on 16 islands within four habitats formed the basis of this study. Half of these islands had mongoose present whilst the other half were known to be mongoose free. Our results showed that skink abundances on mongoose free islands were approximately five times higher than when mongoose were present, irrespective of habitat type. We conclude that it was very likely that mongoose severely supressed even commonly found skink species across all the habitat types on these small islands. Conservation actions that could protect these native species include biosecurity mechanisms to prevent secondary invasion of introduced predators, habitat protection and management, and captive rearing programs. Failure to implement such actions now could result in even common species being at risk of extirpation.
\end{abstract}

*E-mail: Craig.Morley@waiariki.ac.nz

This early view paper has been peer-reviewed and accepted for publication in Pacific Science. However, it has not been copy-edited nor has it undergone typesetting for Pacific Science. The final published paper will look different due to formatting changes, but scientific content will remain the same. 


\section{Introduction}

Emoia skinks, to which Emoia cyanura (the brown-tailed copper-striped skink) and E. impar (the blue or azure-tailed skink) belong, are a large group with marked radiation on Pacific islands (Zug 1991). Skinks can reach extremely high densities on islands (Rodda et al. 2001) and $E$. cyanura is recognised as the most abundant and widespread skink throughout the Pacific (Ineich and Zug 1991). About $19 \%$ of the world's reptiles are considered to be threatened with extinction, and those found within tropical oceanic islands and freshwater ecosystems are particularly at risk (Böhm et al. 2013). Concerted conservation action is needed if reptiles are to be protected and conserved (Gibbons et al. 2000), especially as general extinction rates are estimated to be occurring at least 1000 times faster than the background rate prior to the impact of humans (Pimm et al. 2014). It is possible, therefore, that even seemingly abundant species such as E. impar and E. cyanura may be at risk of extirpation due to the effects of predation by invasive species, habitat loss and other environmental drivers.

One of the key agents for decline of native and endemic species on tropical oceanic islands are introduced predators (Case et al. 1992). The ecological status of the Fiji Islands has been severely affected by the introduction of feral mammals such as rats (Rattus sp.), cats (Felis catus), dogs (Canis lupus familiaris), and small Indian mongoose (Urva auropunctatus synonyms Herpestes auropunctatus, and H. javanicus), hereafter called mongoose (Patou et al. 2009). The small Indian mongoose was introduced to the Fiji Islands in 1883 to control rats (Gorman 1975), and has been implicated in the decline of skinks, frogs and ground birds (Pernetta and Watling 1978). A second mongoose species, H. fusca was recently discovered in Fiji, further compounding the problem of this introduced predator (Morley et al. 2007). Mongoose are found on many tropical islands throughout the world, and the precise impact of their introduction is not always clear (Hays and Conant 2007). The focus of this study was on the effects that mongoose have on the commonly found skinks E. cyanura and E. impar. 


\section{Materials and Methods}

The Fiji Islands consist of more than 300 islands and the country's territorial limits cover 1.3 million $\mathrm{km}^{2}$, of which $18,333 \mathrm{~km}^{2}$ is land (Ryan 2000). There are two main islands; Viti Levu $\left(10,390 \mathrm{~km}^{2}\right)$ and Vanua Levu $\left(5,535 \mathrm{~km}^{2}\right)$. This study was carried out on 16 small offshore islands selected a priori, where half of the islands had known mongoose populations (Table 1) and was done simultaneously with a study that focused on birds (Morley and Winder 2013).

$<$ TABLE 1 NEAR HERE $>$

Islands were selected following extensive preliminary research and the a priori categorization was confirmed by setting 40-60 mongoose traps (at $200 \mathrm{~m}$ intervals) on each island for an eight day period during the study, in order to confirm whether mongoose were present on each island (Table 1). The overall quality of each island with respect to disturbance due to human activity was also assessed (Morley and Winder 2013). Island quality was scored by the investigator when each island was surveyed using a 1-10 interval-based scale. A score of 1 represented the poorest quality, where the island habitat was highly modified with exotic species dominating the vegetation. A score of 10 represented the highest quality, where there was comparatively little evidence of anthropogenic habitat disturbance and significant tracts of intact primary forest were evident.

The surveys took place during the wet season (Jan-May) in 2002-03 and involved completing four transects within each of the 16 islands (64 transect lines in total). Observations were made using a visual encounter transect technique and were carried out in the morning (8-10am) within

four habitat types that were suitable for skinks: (i) village - areas that consisted of dwellings with open grassland areas and ornamental plants and trees; (ii) inland open exposed rocky outcrops or 
sites away from human disturbance; (iii) grassland or disturbed agricultural areas; (iv) shoreline within the short vegetation. The order in which the four habitat types were surveyed on each island was randomized. The starting location of each transect was randomly selected within each habitat, was $25 \mathrm{~m}$ in length and was marked with a rope because each transect was then surveyed for five consecutive dry-weather days. All skinks seen within the $2 \mathrm{~m}$ of the transect line were counted (and any individuals $>2 \mathrm{~m}$ noted). The two skink species (E. cyanura, and E. impar) were counted together to form one overall skink count as it was not always possible in this study to definitively distinguish between the two species by sight (because of the limited time that individuals were visible). It should be noted that E. cyanura, and E. impar have distinct ecologies. E. impar is a typical forest species and more arboreal than E. cyanura and differences in egg-laying habits probably exist (Ineich 1997).

Data were pooled from the five days of sampling and a single count recorded. These data were analyzed using a two-factor mixed factorial ANOVA (SPSS, version 18), with habitat defined as a within-subject factor, mongoose presence defined as a between-subject factor and island quality defined as a covariate. Island quality was included as a covariate because we knew that it had a substantial effect on bird communities from our previous study (Morley and Winder 2013) and hypothesized that it would also affect skinks.

\section{Results}

In total, 4311 skink sightings were made across the 16 islands and four habitats. Data were $\log _{10}$ transformed prior to analysis and Mauchly's test was non-significant $(\mathrm{P}=0.972)$, demonstrating no evidence of heterogeneity of covariance. The presence of mongoose had a significant effect on skink counts $(\mathrm{F}=10.4, \mathrm{P}<0.001$, d.f. $=1,13)$. No habitat $(\mathrm{F}=1.7, \mathrm{P}=0.18$, d.f. $=3,39)$, habitat* quality interaction $(\mathrm{F}=1.9, \mathrm{P}=0.13$, d.f. $=3,39)$ or habitat*mongoose interaction $(\mathrm{F}=1.6$, 
$\mathrm{P}=0.21$, d.f. $=3,39)$ effects were evident. Similarly, the covariate, Island Quality, had no measurable effect $(\mathrm{F}=0.2, \mathrm{P}=0.7$, d.f. $=1,13)$. Hence, results from the study demonstrated that skinks were distributed across all habitat types surveyed equitably but the presence of mongoose appeared to substantially suppress their abundance (Table 1; Fig. 1).

$<$ FIGURE 1 NEAR HERE $>$

\section{Discussion}

Introduced mongoose have long been considered the causal agent for the decline of endemic species on many small tropical islands (Ulrich 1931; Corke 1987; Hays and Conant 2007; Barun et al. 2011). Whilst being unable to prove causality (because a post hoc survey rather than an experimental study was done), our results were consistent with mongoose severely supressing skink populations across all the habitat types studied. This finding was consistent with the study by Case and Bolger (1991) who surveyed 18 islands within the wider South Pacific and with studies on Kyushu and Amami-Oshima Islands in Southern Japan (Watari et al. 2008; Watari, Nagata and Funakoshi 2011). Other studies that indicate skink decline include those conducted in Puerto Rico where mongoose were recorded eating Anolis spp. lizards, the extirpation of the ground lizard (Ameiva polops) in St. Croix, and, on the main islands of Fiji, the extirpation of $E$. nigra and E. trossula (Baskin and Williams 1966; Zug 1991). Similarly, on Christmas Island, Smith et al. (2012) found that five of the six native skink species declined to near extinction due to predation from introduced mammals, centipedes and the yellow crazy ant (Anoplolepis gracilipes) whilst the extirpation of the Pacific skink E. impar in Hawai'i was attributed to the introduced big-headed ant Pheidole megacephala (Fisher and Ineich 2012). Skinks also face a multitude of other agents responsible for their decline; the grand skink (Oligosoma grande) and Otago skink (O. otagense) have declined in New Zealand due to habitat degradation, for example (Houghton and Linkhorn 2002). 
Species are becoming extinct at an alarming rate (Böhm et al. 2013; Pimm et al. 2014), and mongoose are clearly a causal agent of decline of native reptiles within the Pacific and beyond. Unless there is a concerted effort to stem the tide of this invasive pest, then we are probably merely documenting the decline of this ecologically important group of small terrestrial vertebrates. In terms of priority, the adoption of biosecurity strategies to prevent mongoose from reaching other islands appears vital (Morley 2004; Morley and Winder 2013), whilst the use of technology to control and possibly eradicate mongoose from infested islands (Barun et al. 2011) should also be considered. Prioritisation of the prevention of mongoose from invading islands is pragmatic, given that controlling mongoose is fraught with problems and so prevention costs are likely to be much lower than attempting removal. If resources were available, eradication of mongoose on islands would also clearly provide substantial conservation benefit. Mongoose control and eradication could be trialled: in this study the biologically diverse and rich Kioa Island and the small yet degraded island of Yanuca would be ideal candidate islands. Yanuca Island is close to Suva, Fiji's capital, where labour and resources could be accessed so reinvasion would be less likely. Yanuca could provide an excellent opportunity to test if mongoose can be successfully eradicated. Kioa is a short distance from Vanua Levu and mongoose had never invaded the island until they were deliberately introduced. Watari et al (2013) and Fukasawa et al (2013) showed that when mongoose were controlled on other Pacific islands, the density of several native species recovered to the level of the carrying capacity of the island, so such an experiment could prove fruitful in Fiji.

Other actions such as trapping or poisoning mongoose by implementing bounty systems, developing on-site management techniques to improve habitat quality, and rearing skinks in captive management programmes should also be evaluated. However, bounty systems, even when using professional hunters, do not always work as demonstrated by attempts in New Zealand with the Rabbit Boards (Nightingale 1992). Nevertheless, because of the documented 
impact of mongoose (Case and Bolger 1991; this contribution), we call for a concerted attempt within the Pacific to improve biosecurity measures between the inner islands of Fiji and advocate a feasibility study to control or eradicate mongoose. Implementation of prevention and management strategies is needed now, before some stochastic event or additional invasion occurs to extirpate skinks or other affected species on these small offshore islands.

\section{Acknowledgments}

We thank Dick Watling, Tom Dunn, Gunnar Keppel, and Marika Tuiwawa for their advice and assistance in island selection. We also thank the Fijian communities on all the islands visited and for their assistance with the data collection, the Roko Tui's of each region for their permission to conduct this work, the Fijian Provincial Officers for their advice and travel assistance, and Fiji's Ministry of Environment. We would also like to thank two anonymous referees and the editor who helped us to substantially improve our manuscript. 
Table 1. Islands included in the study (Morley \& Winder, 2013). Island quality was scored on a 1-10 scale by the investigator. Total skink count records overall number of individuals observed across all habitats. Number of mongoose trapped records number of individuals caught on each island over an eight day period using 40-60 traps.

\begin{tabular}{lcccccc}
\hline \multicolumn{1}{c}{ Island } & $\begin{array}{c}\text { Island } \\
\text { Size (km } \mathbf{~}^{2} \text { ) }\end{array}$ & Elevation $\mathbf{( m )}$ & $\begin{array}{c}\text { Distance to } \\
\text { mainland island } \\
(\mathbf{k m})\end{array}$ & $\begin{array}{c}\text { Island } \\
\text { quality }\end{array}$ & $\begin{array}{c}\text { Total } \\
\text { skink } \\
\text { count }\end{array}$ & $\begin{array}{c}\text { Number } \\
\text { of } \\
\text { mongoose } \\
\text { trapped }\end{array}$ \\
\hline $\begin{array}{l}\text { Mongoose absent } \\
\text { Moturiki }\end{array}$ & 10.9 & 132 & 2.5 & 7 & 483 & 0 \\
Viwa & 0.6 & 49 & 0.95 & 7 & 463 & 0 \\
Dravuni & 0.8 & 111 & 12.8 & 2 & 673 & 0 \\
Laucala & 12.2 & 265 & 0.5 & 9 & 400 & 0 \\
Vatulele & 31.3 & 33 & 31.8 & 7 & 409 & 0 \\
Koro & 104 & 561 & 48 & 8 & 352 & 0 \\
Naviti & 34 & 338 & 49.6 & 3 & 455 & 0 \\
Waya & 22 & 502 & 12.1 & 3 & 467 & 0 \\
Mongoose present & & & & & & \\
Beqa & 36.2 & 439 & 9.63 & 3 & 36 & 78 \\
Nananu-i-ra & 2.7 & 73 & 0.78 & 2 & 157 & 23 \\
Malake & 4.5 & 219 & 2 & 1 & 22 & 78 \\
Kioa & 18.6 & 305 & 0.8 & 9 & 104 & 43 \\
Yanuca & 1.5 & 137 & 9.8 & 1 & 40 & 13 \\
Nananu-i-cake & 3 & 73 & 0.63 & 3 & 168 & 13 \\
Macuata-i-wai & 3 & 184 & 1.76 & 1 & 35 & 46 \\
Rabi & 68.8 & 463 & 5.4 & 6 & 47 & 45 \\
\hline
\end{tabular}




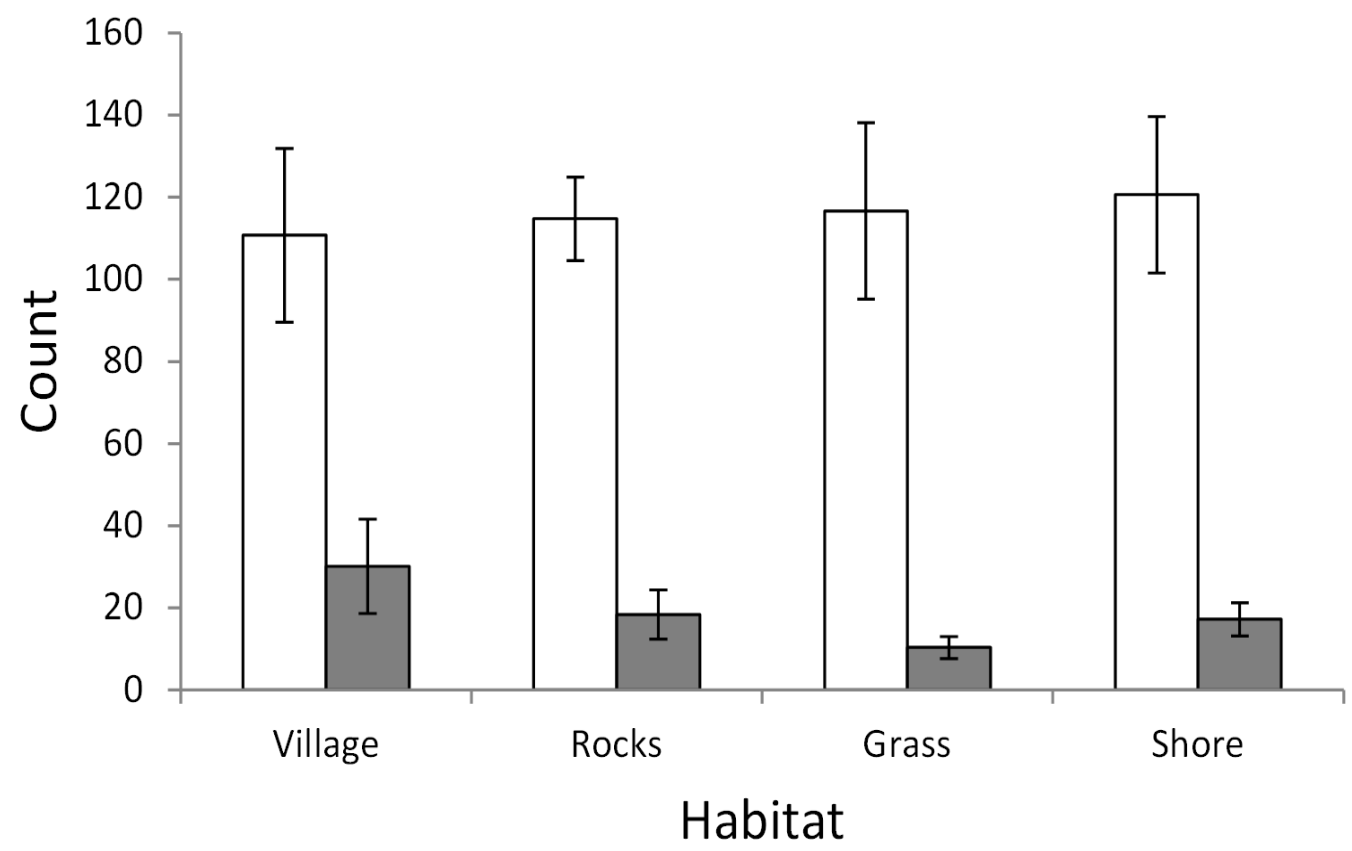


Figure 1. Skink counts recorded over a five day period (mean $\operatorname{transect}^{-1} \pm 1$ s.e.) within four habitat types on islands where mongoose were absent (open bars) and present (filled bars). 


\section{Literature Cited}

Barun, A., C.C. Hanson, K.J. Campbell, and D. Simberloff. 2011. A review of small Indian mongoose management and eradications on islands. In: Veitch, C. R., M. N. Clout, and D. R. Towns (eds.). Island invasives: eradication and management. IUCN, Gland, Switzerland. Pp 1725.

Baskin, J.N., and E.E. Williams. 1966. The lesser Antillean Ameiva (Sauria, Teiidae). Stud. Fauna Curacao and Carb Isl. 89: 144-176.

Böhm, M. et al. 2013. The conservation status of the world's reptiles. Biol. Cons. 157:372-385.

Case, T., and D.T. Bolger. 1991. The role of introduced species in shaping the distribution and abundance of island reptiles. Evol. Ecol. 5:272-290.

Case, T. J., D.T. Bolger, and A.D. Richman. 1992. Reptilian extinctions: The last ten thousand years. Pages 91-125. In: Fiedler, P. L. and S. K. Jain, eds. Conservation Biology. Chapman and Hall. New York.

Corke, D. 1987. Reptile conservation on the Maria Islands (St. Lucia, West Indies). Biol. Cons. 40:263-279.

Fisher, R., and I. Ineich. 2012. Cryptic extinction of a common Pacific lizard Emoia impar (Squamata, Scincidae) from the Hawaiian Islands. Oryx 46:187-195. 
Fukasawa, K., T. Miyashita, T. Hashimoto, M. Tatara, and S. Abe. 2013. Differential population responses of native and alien rodents to an invasive predator, habitat alteration and plant masting. Proceedings of the Royal Society B 280:20132075.

Gibbons, J.W., D.E. Scott, T.J. Ryan, K.A. Buhlmann, T.D. Tuberville, M.S. Metts, J.L. Greene, T. Mills, Y. Leiden, S. Poppy, and C. Winne. 2000. The global decline of reptiles, déjà vu amphibians. BioScience 50: 653-666.

Gorman, M. L. 1975. The diet of feral Herpestes auropunctatus (Carnivora: Viverridae) in the Fijian Islands. J. Zool. Lond. 175: 275-278.

Hays, W.S.T., and S. Conant. 2007. Biology and impacts of Pacific island invasive species. A worldwide review of effects of the small Indian mongoose, Herpestes javanicus (Carnivora: Herpestidae). Pac. Sci. 61: 3-16.

Houghton, C., and R. Linkhorn. 2002. Population decline in the skinks Oligosoma otagense and O. grande at Macraes Flat, Otago. Unpublished Department of Conservation Science Internal Series Report 32, Pp. 26.

Ineich, I. 1997. Natural History Notes - Emoia impar (Blue-tailed Pacific Copper-stripped Skink). Reproduction. Herpetological Review 28: 43.

Ineich I., and G.R. Zug. 1991. Nomenclatural status of Emoia-cyanura (Lacertilia scincidae) populations in the central pacific. Copeia 1991:1132-1136. 
Morley, C.G. 2004. Has the invasive mongoose Herpestes javanicus yet reached the island of Taveuni, Fiji? Oryx 38:457-460.

Morley, C.G., and L. Winder. 2013. The effect of the small Indian mongoose (Urva auropunctatus), island quality and habitat on the distribution of native and endemic birds on small islands within Fiji. PLoS ONE 8:doi:10.1371/journal.pone.0053842.

Morley, C. G., P. A. McLenachan, and P. J. Lockhart. 2007. Evidence for the presence of a second species of mongoose in the Fiji Islands. Pac. Con. Bio. 13:29-34.

Nightingale, T. (1992). White collars and gumboots: a history of the Ministry of Agriculture and Fisheries, 1892-1992, Dumore Press, Palmerston North. P 277.

Patou, M.L., P.A. Mclenachan, C.G. Morley, A. Couloux , C. Cruaud. A.P. Jennings, and G. Veron. 2009. Molecular phylogeny of the Herpestidae (Mammalia, Carnivora) with a special emphasis on the Asian Herpestes. Mol. Phyl. Evol. 53:69-80.

Pernetta, J. C., and D. Watling. 1978. The introduced and native terrestrial vertebrates of Fiji. Pac. Sci. 32: 223-244.

Pimm, S.L., C.N. Jenkins, R. Abell, T.M. Brooks, J.L. Gittleman, L.N. Joppa, P.H. Raven, C.M. Roberts, and J.O. Sexton. 2014. The biodiversity of species and their rates of extinction, distribution, and protection. Science 344:doi: 10.1126/science.1246752. 
Rodda, G.H., G. Perry, R.J. Rondeau, and J. Lazell. 2001. The densest terrestrial vertebrate. J. Trop. Ecol. 17:331-338.

Ryan, P. A. 2000. Fiji's natural heritage. Exisle Publishing. Auckland, New Zealand.

Smith, M.J., H. Cogger, B. Tiernan, D. Maple, D. Boland, F. Napier, T. Detto, and P. Smith. 2012. An oceanic island reptile community under threat; the decline of reptiles on Christmas Island, Indian Ocean. Herp. Conserv. Biol. 7:206-218.

Ulrich, F.W. 1931. The mongoose in Trinidad. Trop. Agr. 8:95-97.

Watari, Y., S. Takatsuki, and T. Miyashita. 2008. Effects of exotic mongoose (Herpestes javanicus) on the native fauna of Amami-Oshima Island, southern Japan, estimated by distribution patterns along the historical gradient of mongoose invasion. Biol. Invasions 9:7-17.

Watari, Y., J. Nagato, and K. Funashiko. 2011. New detection of a 30-year-old population of introduced mongoose Herpestes auropunctatus on Kyushu Island, Japan. Biol. Invasions 13:269279.

Watari, Y., S. Nishijima, M. Fukasawa, F. Yamada, S. Abe, and T. Miyashita. 2013. Evaluating the "recovery-level" of endangered species without prior information before alien invasion. Ecol. Evol. 3:4711-4721.

Zug, G. R. 1991. The lizards of Fiji: Natural history and systematics. Bishop Mus. Bull. Zool. 2:1-136. 